\title{
The Practice Teaching of Journalism: Empirical Observation and Theoretical Construction
}

\author{
Zhang Qin ${ }^{1, \text { a }}$, Zhang Juan ${ }^{2, \mathrm{~b}}$ \\ ${ }^{1}$ College of Art and Communication, Three Gorges University, Yichang, 443002, China \\ ${ }^{2}$ College of Art and Communication, Three Gorges University, Yichang, 443002, China \\ aemail: wszhangqin@ctgu.edu.cn, bemail: ctguzhangjuan@163.com
}

Keywords: Journalism; practice teaching; empirical observation; theory

\begin{abstract}
The paper discusses the evaluation criteria of journalism practical teaching quality on the basis of concept definition, studies and analyzes the issues that related to the level of present journalism practice teaching of most local colleges in China. Besides, the paper tries to make a primary study on the possibilities of optimizing and improving the level of journalism practice teaching of local colleges in China by discussing the questions like the relationship between the transformation of practical teaching concept and the promotion of practical teaching level.
\end{abstract}

\section{Introduction}

Chinese journalism education in colleges in the $21^{\text {st }}$ century increasingly inclines to cultivating students' practical operation ability, which is adapt to the changes and challenges that journalism education faces. "National medium and long-term educational reform and development project summary (2010-2012)"clearly states that great efforts should be make to improve students' innovation spirit and the practice ability of solving problems. There's no doubt that the motivation of journalism education is to train talents for the news industry. However, it is the true fact that the current university journalism education has divorced from the needs of media[1], so how to improve the situation? In recent years, many journalism education papers put forward lots of solutions and methods, mainly include: (1) curriculum and teaching method reform. Bases on the development status of media, renews educational concepts. (2) optimization of the teaching staff. Constructs the "double teacher type" team to meet the needs of the development of media industry. (3)extensive cooperation between colleges and media. Tries to build the platform of collaborative innovation that connected with the media. (4)construction of specialized laboratories. Runs the experimental media.

However, the journalism in colleges especially in the local colleges, the human, material and social resources cannot meet the needs of the above four practical teaching methods for a long time, so facing the teaching present situation of journalism education, a series of problems need to discuss: what's the result of journalism practice teaching? How to evaluate the level of practice teaching? How to face the regional differences of journalism education in China? And how to balance the scales between practice teaching and theory teaching in journalism curriculum system? The paper hopes to join the above discussion by exploring the problems like the relationship between the transformation of practical teaching concept and the promotion of practical teaching level.

\section{The Evolution History of the Chinese and Foreign Journalism Education Concept and its Enlightenments to the Journalism Practice Teaching}

There has a consensus in global journalism that general education, basic education of professional discipline and professional education of journalism constitute three basic aspects of journalism education. Undoubtedly, on the issue of balance of theory and practice, American journalism education system is more reasonable and mature than other countries.

The Taiwan scholar, Chen Ming once summarized the American journalism teaching model as follows: bases on the practice training, returns to the social sciences and ends to the humanism[2]. The American journalism educational concept that ingrained with vocational education orientation 
admires this way of teaching mode: master train an apprentice, and the best practice site it approves is the industry than the academia. In order to fully seek the industry's recognition to college journalism education, the Missouri University in 1908 established the first student practice base -university of Missouri people newspaper. This newspaper not only issued to the university campus, but also to the public. After that, puts more emphasis on practice training has gradually become the basic concept of journalism practice education in American universities.

Of course, with the development of journalism and the continuous renewal of media technology, the practice methods of journalism of American colleges are constantly enriched. In this regard, many Chinese scholars who have personally visited United States summarized these methods as follows: (1) attached importance to the cultivation that the socialized campus media acted on the students' practical ability. Whether own socialized campus media or not is one of the important conditions for U.S News and Mass Communication Educational Assessment Certification Institute to evaluate the school qualifications of journalism education. (2) created the studio course. Cai Ming, the professor of Renmin University of China, has written about a variety of studio courses of the journalism school of Columbia[3]. (3) in addition to classroom teaching, there are the short-term training courses that set up by a variety of institutes or the business skills training that organized by various associations, to help the students or professional journalists continue to their skill training.

United States is the founder of the world journalism education, its educational concept and mode also have great influence on the Chinese journalism education. The history of Chinese journalism had experienced three periods. The first period, we imitated American journalism education model, relied on the journalism educational concept of cultivating generalists and valuing practice (1919-1949); the second period, we copied soviet model, relied on cultivating special talents and valuing politics (1949-1979); the third period, we relied on cultivating interdisciplinary talents and valuing comprehensive quality and humanistic spirit. However, as to the general education, special education and complex talents education, no matter which ones we chose, the practice teaching is the core content of the journalism education.

Combining the history of Chinese and foreign journalism educational concept provided us some enlightenments about journalism practice teaching: journalism professional skills and the humanities, which was the essential? And which was the superficial? Which is more important to college journalism teachers- doctorate and media experience? How to establish the quality evaluation system and practice teaching feedback? Only to think about how to solve these problems, can we change the concept of journalism practice teaching and improve the level of practice teaching effectively.

\section{The Connotation of Journalism Practical Teaching Curriculum System}

The consideration of keeping balance of skills and theory in journalism curriculum reveals the particularity of the journalism education. It is a hybrid that mixed professional conduct system with education system. In other words, journalism education should be a new vocational system that could meet the needs of society and achieve the goals of higher education[4]. We believe that the journalism teaching course system should include two aspects: (1) lectures: the practice contents sets in the theory course. (2) expanding extra-curriculum: the practice contents sets in the internships course. The integration point of the two aspects is to think about how to better combine theoretical classroom teaching, campus laboratory teaching with the participation in the "actual combat" of social media.

With the unceasing change of current news format, journalism class practice teaching also should keep pace with the times. Innovative teaching method is a guarantee of good result of internship. Among them, practical teaching methods that attaches great importance to the combination of theory and practice become the new exploration for training talents in media era. The "point team" of Huazhong University of Science and Technology provides us some experiences in this field, which is created by professor Liu Yu in march 2002, full name is "tutorial system-based undergraduate talent incubating station". The teaching methods are mainly to help students form studios that based on teacher' projects, which make the one-way transmission type between teachers and students into a 
two-way interactive communication in journalism theory education. Not the same with the practice methods like "point team”, Lixi Guang, the professor of Tsinghua University, pursues the "walking practical method", he once led the students to do the new Long March, got into mine for interview miners, went to the Taihang Mountain where the eighth Route Army fought the Japanese devils. He insists on letting students dig wonderful stories in the lives of ordinary people and learn the theories and actual ability of the journalism practice course in the real world.

Of course, training students' journalism actual ability not only should pay attention to comprehensive simulation training in the school curriculum but also should participate in outside work-related internships, aims to achieve the goal of "real-time interaction". The platform for cooperation and exchanges between media and university become an important part of the combination of theory education and practice education. At the same time, it also an important means to enhance the mutual understanding between media and universities. The platform can not only temper students' ability, improve their professionalism and humanistic quality, and can promote media and colleges work together to cultivate excellent journalism talents and eventually achieve win-win. There are various ways to promote the internal and external combination, among them, the most representative ways are as follows: establishes the journalism experiment center that connected with the operation of media, widely establishes practice bases, invites experts and scholars to give lectures, etc. In the study of the innovation of teaching methods, we should attach great importance to the combination of individual and collective. Practice shows that news reports focus on teamwork; the large reports particularly need the coordination of the front and the rear, and the unity of the collecting, editing and broadcast. Therefore, enough emphasis should be put on cultivating students'team spirit in the daily teaching.

\section{The Evaluation Criteria of Journalism Practical Teaching Quality}

Starting from the goal of cultivating talents, journalism education should take the cultivation of application ability and innovation ability as the core, and handle the relationship between the theory teaching and practice teaching. Thesis (design), experiment teaching, internship can be serve as the main line of the first class in journalism practical teaching curriculum, and academic competition, technology innovation, extra-curricular science and technology and entrepreneurship can be serve as auxiliary and supplementary of the second class activities to achieve the combination between the intramural comprehensive simulation training and extramural professional internship, it is a hierarchical, interconnected practical teaching system. Among them, the second class activity that presented by the academic competition is not only the carrier of journalism practice education, but also the means and tools of the quality detection of talent cultivation. Therefore, we believe that the activity quality of the second class that represented by academic competition can be a basic standard to evaluate the quality of the journalism practice teaching. The standard shed light on how to cultivate students' basic quality and skills, innovative spirit, practical ability and promoting the teaching reform, which deserves to explore unceasingly in the journalism practice teaching.

Summarized the scholars' paper that related to the academic competition, we known that the functions of the academic competition are as follows: (1) to improve the quality of education teaching. Academic competition can promote teachers to get access to information, consolidate their own teaching skills, and convert the experience of academic competition training to the important contents of classroom teaching. (2) to promote the cooperation between the colleges and enterprises. Many employers hope to find the necessary talents through competition. (3) to promote the cultivation of the abilities of students. One of the goals of academic competition is to test students' knowledge, which is beneficial to improve their comprehensive quality, thus to better achieve the purpose of employment and meet the demands for talents of society[5].

In a word, the academic competition of journalism can effectively extend the teaching to the outside of the classroom and campus, becomes the important guideline that could guide the teaching practical links scientifically, monitor the practice teaching effectively, and evaluate the achievements of practice teaching soundly. 


\section{The Cultivation of Innovative Talents and the Reform of Practical Teaching Mode}

One of the important missions of the college journalism education is to cultivate innovative talents. There are many approaches to cultivate talents, meanwhile the academic competition play an important role in the cultivation of innovative talents.

Colleges how to make use of their own resource advantages to encourage students' enthusiasm for the scientific and technological innovation, and build the platform connected with enterprises for lateral communication. Takes the competition as an opportunity to develop innovative practice activities, and with the competition to detect teaching effectiveness of innovative practice, they are one of the elements of higher education reform of current teaching. Therefore, in the media age, the construction of the journalism practical teaching mode can be take academic competition as incentive, school- enterprise cooperation as platform and innovative entrepreneurship as guidance.

\section{A. Academic Competition as Incentive}

The second class that based on academic competition can greatly stimulate students' enthusiasm for learning, exercise and reflect their innovation consciousness, innovation ability and personality. In January 2007, the Ministry of Education, the Ministry of Finance jointly issued "the Ministry of Education, the Ministry of Finance on the implementation of undergraduate teaching quality and teaching reform project of the higher school”, it clearly put forward that we should continue to develop competition activities of college students, focus on financing in these competitions that have a great influence in the country and have a wide range of participants. In this way, it aims to stimulate the interest and potentials of college students, and cultivate their teamwork consciousness and innovation spirit. Thus, with country' support for competition and the increasing of enterprise competition projects, colleges are urgent need to explore how to utilize academic competition to promote the teaching quality and deepen into the teaching reform in the new situation.

\section{B. School-Enterprise Cooperation as Platform}

Modern journalism education, especially radio and television journalism education, is a science in liberal arts. The equipment system of experiment teaching as well as the establishment and operation of the related media platform need to invest huge amounts of money. Currently, in our country, the investment funds for equipments and teaching management that referred to the general liberal arts education cannot meet the above requirements. In this regard, a lot of journalism departments in addition to continuing to apply for the funds from the competent authorities, striving to gain the funds that similar with science, the emphasis they should put more on seeking the financial support of the society. In China, due to the lack of awareness and tradition of denoting funds for school, and lack of the appropriate policy guidance, thus in the short-term we cannot obtain the capital scale that similar with America (accounts for about $40 \%$ of the funds ) by the mode of donating. Therefore, we should make full of alumni resources, local enterprise recourses, as well as overseas Chinese resources and the regal resource of Hong Kong, Macao and Taiwan, adopt flexible policy and operation, reduce the threshold of the donation, cooperate with the enterprise and build the collaborative innovation platform. For example, the authorized non-government project company undertakes the investment, finance construction, operation and maintenance of the project, in the concession period stipulated by the agreement, the project company not only could charge appropriate fees to the school users, but also could provide services to the public on the basis of meeting the demands of the school, by this way to recycle costs and obtain a reasonable return, after the concession period, the project company transfers the facilities to the school for free.what's more, we should cooperate with the media, gradually carry out two-way cooperation between the campus media and social media, share equipments and information resources, obtain the multi-valued goal of media information and strive to explore a variety of implementation patterns like the “ordering-form”, “combining of production, teaching and research”.

\section{Innovative Entrepreneurship as Guidance}

Innovation capability is the main emphasis of talents training in today's society, of course, is also a prerequisite of news talent of the $21^{\text {st }}$ century. The basic goal that the integrated practical teaching 
mode pursuits is enable students to own better employment quality and employability through learning and training; the highest goal of the intensive training is to build students' creative ability. Encourages students to innovate boldly in intensive training with various media and forms in the former three years of university. From the macro level of newspaper running model, design of campus site to the medium level of program (column) design, news planning, and to the micro level of interview design, the angle selection of news writing, the methods can fully simulate the students' potential. Besides, the most important thing is to arrange a semester professional internship in senior year. In this period, the level of media requires relatively high and the assessment requirement requires relatively increasing, to enable students to fully integrate into the journalism works and seek a comprehensive breakthrough and innovation on jobs skills, work connotation and work efficiency through the intensive training in the end.

\section{Conclusion}

Why journalism majors are so difficult in looking for a work currently? Why journalism majors couldn't compete with the students of other academics? The reason is that some students' practice ability is so poor that lost their core competitiveness, hence leads to the knowledge they have learned cannot show difference in the competition.

Therefore, the future journalism education in colleges should pay more attention to the cultivation of student' practice ability, especially to develop their basic quality and ability---enable them to have extraordinary news sensitive, observation skills, social skills and master the basic techniques of news writing, operate technical equipments skillfully. Meanwhile, the colleges also should attach importance to improving students' distinctive competitiveness. At present, news reform is in full swing, division of labor within the media is more and more detailed, especially news gathering and editing. Journalism education in colleges also need to adapt to this new change and enable students to improve their distinctive competitiveness, thus refining the orientation of talent cultivation is the main task of journalism education.

In short, attaches importance to the journalism practice education is to pay attention to the harmony and balance of theory and practice. We need to use the developing approaches to solve the problems that brought by the development, with the hope of promoting the journalism education to embark on the track of sound development.

\section{Acknowledgment}

The authors grateful thanks the financial support of the Key Program of Education Research in 2012 of Three Gorges University(Grant No. 1211 ), the Scientific Quality Program in 2012 of West Anhui University(Grant No. 2012jy15 ).

\section{References}

[1] Chen Yong, Wangyuan Zhou, Wuxiao Hua. Survey on the Journalism Education of Colleges and Its Connected with Media[J]. Press Circles. Sichuang: Chengdu, 2008, pp. 145-146.

[2] Zhengzhen Ming. Chinese and Foreign Journalism Education [D].Taibei:Taiwang origin publishing enterprise co,ltd, 1999, pp. 28-36.

[3] Cai Wen, Zhouxin Feng. A Classical Case of America journalism Education Reform (on) [J]. Journal of International Communication, Chengdu, 2005

[4] Chenjun Ni, Chenjun Feng. Form of Professionalism and Form of Education: Ten Core Questions about Journalism Education[J].Journal of International Communication, Beijing, 2011, pp.13-24.

[5]Wan Min. Constructing College Student Ability Training Mode based on Academic Competition[J]. Journal of Xichang College (natural science edition), 2001,3 